\title{
A retrospective analysis focusing on a group of patients with dual diagnosis treated by both mental health and substance use services
}

This article was published in the following Dove Press journal:

Neuropsychiatric Disease and Treatment

II August 2014

Number of times this article has been viewed

\section{Rosaria Di Lorenzo' \\ Agnese Galliani² \\ Alessia Guicciardi ${ }^{3}$ \\ Giulia Landi ${ }^{3}$ \\ Paola Ferri ${ }^{2}$}

'Mental Health Department, Azienda USL di Modena, Modena, Italy; ${ }^{2} \mathrm{School}$ of Nursing, University of Modena and Reggio Emilia, Modena, Italy; ${ }^{3}$ Department of Psychiatry, University of Modena and Reggio Emilia, Modena, Italy
Correspondence: Rosaria Di Lorenzo SPDC, NOCSAE, via Giardini I355, 4I I 26 Baggiovara, Modena, Italy

Tel +39335 54l 0018

Fax +39059396 I379

Email saradilorenzoI@alice.it;

r.dilorenzo@ausl.mo.it
Objective: To highlight which demographic, familial, premorbid, clinical, therapeutic, rehabilitative, and assistance factors were related to dual diagnosis, which, in psychiatry, means the co-occurrence of both mental disorder and substance use in the same patient.

Methods: Our sample $(\mathrm{N}=145)$ was chosen from all outpatients with a dual diagnosis treated from January 1, 2012 to July 31, 2012 by both the Mental Health Service and the Substance Use Service of Modena and Castelfranco Emilia, Italy. Patients who dropped out during the study period were excluded. Demographic data and variables related to familial and premorbid history, clinical course, rehabilitative programs, social support and nursing care, and outcome complications were collected. The patients' clinical and functioning conditions during the study period were evaluated.

Results: Our patients were mostly men suffering from a cluster B personality disorder. Substance use was significantly more likely to precede psychiatric disease $(P<0.001)$, and $60 \%$ of the sample presented a positive familial history for psychiatric or addiction disease or premorbid traumatic factors. The onset age of substance use was related to the period of psychiatric treatment follow-up $(P<0.001)$ and the time spent in rehabilitative facilities $(P<0.05)$, which, in turn, was correlated with personality disorder diagnosis $(P<0.05)$. Complications, which presented in $67 \%$ of patients, were related to the high number of psychiatric hospitalizations $(P<0.05)$ and professionals involved in each patient's treatment $(P<0.05)$. Males more frequently presented familial, health, and social complications, whereas females more frequently presented self-threatening behavior $(P<0.005)$.

Conclusion: It was concluded that the course of dual diagnosis may be chronic, severe, and disabling, requiring many long-term therapeutic and rehabilitative programs to manage various disabilities.

Keywords: dual diagnosis patients, mental health and substance use services, mental disorder and substance use co-occurrence

\section{Introduction}

In psychiatry, the term "dual diagnosis" and other interchangeable terms (eg, comorbidity, co-occurring illnesses, concurrent disorders, dual disorder, double trouble) mean the co-occurrence of both a mental health disorder and substance use in the same patient. ${ }^{1,2}$ The occurrence of dual diagnosis is quite common: Regier et $\mathrm{al}^{3}$ reported that $44 \%$ of alcohol abusers and $64.4 \%$ of illegal substance abusers suffered from a major mental disorder, whereas Kessler et $\mathrm{al}^{4,5}$ found that persons affected by alcohol or illegal drug dependence presented a mental disorder 4.1 times and 4.9 times more frequently, respectively, than non-alcohol-dependent people. 
Other studies have shown that $56 \%$ of patients suffering from a substance use disorder had a mental disorder at the same time ${ }^{6}$ and that from $18.5 \%$ to $50.0 \%$ of patients with a substance use disorder had received psychiatric treatment during their lifetimes. ${ }^{7-9}$

Among dual-diagnosis patients, substance-use disorders range from single drug abuse to cocktails of substances, whereas mental health problems include both a wide range of disorders, from those defined as "high-prevalence and lowimpact therapeutic", such as anxiety and depression, to those defined as "low prevalence, high-impact therapeutic", such as psychosis and major mood disorders. Although the "low impact" group is the most represented among dual-diagnosis patients, the "high impact" group, even if smaller, requires more intensive and expensive treatment programs. ${ }^{10}$ The co-occurrence of the abovementioned disorders increases the severity of symptoms and difficulty of treatment, with worse physical, psychological, and social outcomes. ${ }^{10}$ The clinical and rehabilitative needs of dual-diagnosis patients can be extremely different and polymorphic, depending on the level of their functioning, which is usually conditioned by pathological behavior and poor therapeutic compliance. ${ }^{11,12}$

Neurobiological models attribute the key role in the development of addiction to the brain's reward system via the dopaminergic mesocorticolimbic pathway. ${ }^{13}$ The vulnerability to addiction development is frequently associated with genetic factors and personality traits. Recent studies highlighted that both alcohol-dependent and opiate-dependent patients have common genetic variants in dopamine D2 receptors and serotonin-transporter-linked promoter region associated with higher frequency to novelty-seeking personality traits. ${ }^{14}$ Impulsivity, perhaps the most widely studied personality trait in the addiction literature, represents a predictor of future problems with substance use, due to its biologically-based link to additive core processes, ${ }^{15}$ and is closely associated with alcohol use, especially in individuals with poor workingmemory capacity. ${ }^{16}$

Personality disorders are considered the most important predictors of treatment outcome in drug abusers. Borderline personality disorder is associated with high lifetime rates of substance abuse as well as higher-than-expected rates of charges for various drug-related crimes and criminal behavior. ${ }^{17}$ The comorbidity between cocaine dependence and personality disorders from Clusters B and $\mathrm{C}$ is associated with executive-function deficits. ${ }^{18}$ The National Epidemiologic Survey on Alcohol and Related Conditions ${ }^{19}$ highlighted that individuals with drug use disorder were 2.2 times more likely to present a comorbid personality disorder.
Some studies have identified the Cluster B antisocial and borderline personality disorders as most prevalent across various types of substance abusers..$^{20,21}$

Many researchers found that individuals with dual diagnosis had high rates of a positive family history for substance use and/or psychiatric diseases, which could impact the severity and consequences of dual diagnosis. ${ }^{22,23}$ Other studies evidenced that vulnerability to substance abuse increased among individuals with mental illness who were victimized during childhood ${ }^{24,25}$ and that this relationship induced a range of poor outcomes, including earlier onset and longer duration of substance abuse, worse physical health, and more interpersonal problems. ${ }^{26,27}$

The relationship between substance use and mental disorders has long been debated in order to evidence which of the two diseases could most condition the onset of the other. In adolescents and young adults with a first psychotic episode, co-occurring substance use was reported in $74 \%$ of all cases and was associated with limited response to treatment, decreased medication adherence, and worsened illness course. ${ }^{28,29}$ Psychosis and onset of substance use are often linked: one-third of patients experienced their first psychotic episode before the age of 19 years, and adolescence represents the peak time period for use and experimentation with alcohol, cannabis, and other illicit substances, the capability of which to induce psychotic symptoms has been well established. ${ }^{30-33}$ In particular, cannabis may represent a significant risk factor for the development of psychotic illness in vulnerable individuals. ${ }^{30-34}$ Schizophrenia patients have a higher risk for substance abuse due to degenerating cognitive abilities and disadvantageous life circumstances ("cumulative risk factor hypothesis") or due to a need to reduce their symptoms and to offset the side effects of antipsychotic medication ("self-medication hypothesis"). ${ }^{35,36}$

The co-occurrence of mood and substance use disorders is common and is clinically more severe and more difficult to treat, with considerable psychosocial disability and increased utilization of health care resources, including psychiatric hospitalizations. ${ }^{37-39}$ The lifetime prevalence rate of all bipolar disorders and substance use disorders is $47.3 \%$ and, in particular, for bipolar I and substance use disorders is $60.3 \% .^{40-42}$ Comorbid substance use disorder is frequent in major depression, with lifetime rates of $40.3 \%$ for alcohol use and $17.2 \%$ for all other associated substance use disorders. ${ }^{43}$ Comorbidity between anxiety and substance use disorders is pervasive in the US population. ${ }^{43,44}$ Because mood symptoms may precede or be precipitated by drug and 
alcohol dependence, most authors hypothesize that common risk factors for both diseases, such as stressful events, ${ }^{45}$ psychological trauma, and genetic vulnerability, could lead to co-occurring expression. ${ }^{46,47}$

The aims of the current study were to analyze the clinical course, outcome complications, and assistance-care needs of a sample of dual-diagnosis patients treated by both the Mental Health Service (MHS) and the Substance Use Service (SUS) of Modena and Castelfranco Emilia, Italy, and to highlight which demographic, familial, premorbid, clinical, therapeutic, rehabilitative, and/or nursing-care factors are related to dual diagnosis and can condition its course.

\section{Methods}

\section{Ethical considerations}

This study, conducted in accordance with the principles of the Declaration of Helsinki and good clinical practice, was approved by the Human Subjects Review Committee of Azienda USL di Modena. Written informed consent was obtained from all participants at the beginning of treatments on both of the services after a discussion about treatment and utilization of their demographic and clinical data.

\section{Sample}

Our sample was chosen from all outpatients $(\mathrm{N}=175)$ with dual diagnosis (according to the International Classification of Diseases, 9th revision, Clinical Modification [ICD-9$\mathrm{CM}]^{48}$ in use in our department), treated by both MHS and SUS (catchment area of approximately 250,000 inhabitants) during the period January 1, 2012 to July 31, 2012. After excluding 30 dual-diagnosis patients treated by both services who voluntarily discontinued outpatient treatment during the study period (ie, did not return for subsequent appointments), our sample consisted of 145 dual-diagnosis patients. From the services' medical records, we retrospectively collected demographic data and the variables shown in Table 1 for our sample.

\section{Variables}

\section{Familial and premorbid history}

Family history of psychiatric disorders and/or substance abuse and stressful and/or negative events experienced during childhood or adolescence were analyzed in order to evaluate inherited or acquired predisposal conditions to dual-diagnosis development (Table 1).

\section{Clinical course}

The following variables were chosen in order to identify the clinical complexity of the dual disorder: onset age of substance abuse and psychiatric illness, follow-up period of treatment at MHC and SUS, the kind of substance abused (both at the onset of illness and during the study period), number of psychiatric hospitalizations, psychiatric diagnoses according to the ICD-9-CM, ${ }^{48}$ psychopharmacological treatments, therapies prescribed as substance replacement (eg, methadone, buprenorphine) and/or as an adversative drug (disulfiram), and psychotherapy method used (individual supportive, supportive group, or other kind) (Table 1).

Table I The variables collected in our sample

Familial and premorbid history

Clinical course

Rehabilitative programs, social

support, and professional staffing

Outcome complications

Clinical tests
Positive family history for psychiatric diseases and/or addiction

Significant loss (eg, parent bereavement, family financial ruin, family emigration), trauma (eg, abuse or maltreatment), severe organic diseases during childhood and adolescence Onset age of substance use and psychiatric disorder

Kinds of onset and current substance(s) of abuse

Psychiatric diagnosis

Follow-up period of Mental Health Service and Substance Use Service treatment

Pharmacotherapy for psychiatric disorder and for substance abuse

Number of psychiatric hospitalizations

Psychotherapeutic activities

Time (months) spent in therapeutic community or in psychiatric facilities

Social support (eg, protected job placement, house collocation, economic assistance)

Professional staffing: number of professionals involved in outpatient care

Family, economic, legal, and employment problems, health complications,

self-destructive behaviors, social drift

For severity: Clinical Global Impression-Severity administered at the beginning of psychiatric treatment

For improvement: Clinical Global Impression-Improvement administered during

the period of this study

For functioning: Global functioning Assessment administered at the beginning

of psychiatric treatment and during the period of this study 


\section{Rehabilitative programs, social support,} and professional staffing

The rehabilitative programs were assessed through the months spent either in therapeutic communities or in psychiatric facilities. This represented, in our opinion, the time required to relearn the necessary basic skills to live autonomously. The social service activities consisted of all supportive interventions, such as protected job placement, house collocation, or economic assistance, required by patients due to their social maladaptive situation (Table 1). The level of nursing care was evaluated through the number of professionals involved in each patient's treatment, since the complexity of care activities could range from drug administration or collection of samples for toxicological tests to more complex activities, such as educational and relational approaches for patients with severely impaired functioning (Table 1).

\section{Outcome complications}

The following complications related to dual diagnosis were analyzed: work problems (eg, unemployment, frequent job change, economic crisis), family problems (eg, separation, family abandonment, loss of parental authority), health problems (eg, hepatitis $\mathrm{C}$ virus, HIV infection, alcoholic liver disease, epilepsy), legal problems (eg, revoked driving license, crimes related to substance use or psychiatric illness, detention in prison), self-injurious behavior (self-harm, suicide attempts, dangerous behavior), social problems (eg, isolation, institutional dependence, social drift, prostitution, homelessness) (Table 1).

\section{Clinical tests}

In order to assess clinical and functional aspects of our sample, we collected the Global Impression Scale-Severity $(\mathrm{CGI}-\mathrm{S})^{49}$ and Global Assessment of Functioning (GAF) ${ }^{50}$ scores collected during the first psychiatric evaluation at MHS and recorded in patients' clinical charts. We asked the MHS psychiatrist of each dual-diagnosis patient to evaluate her/his clinical condition during the study period by means of the Clinical Global Impression ScaleImprovement (CGI-I) ${ }^{48}$ and GAF, in order to compare it to the patients' clinical situation at the first psychiatric treatment (Table 1).

\section{Statistical analysis}

Data from the 145 patients in our final sample were statistically analyzed (descriptive statistics, Student's $t$-test, chi-square test, Spearman correlations, simple and multiple linear and logistic regression, survival analyses) using the STATA software program. ${ }^{51}$

\section{Results}

Our sample included 95 males (65.52\%) and 50 females (34.48\%), with $94 \%$ Italians $(n=136)$. The average age in our sample was 44 years for men and 45 years for women.

\section{Familial and premorbid history}

We were not able to obtain reliable information for $34 \%$ of our sample as no familial and/or premorbid elements of anamnesis had been reported in the medical records. We observed that most patients presented a premorbid history (Figure 1), including familial psychiatric illness or substance use (11\%), stressful life events occurring in childhood or adolescence ( $23 \%)$, or both of these conditions $(26 \%)$. We could not correlate these factors with any other variables analyzed. Only $6 \%$ of our patients did not report any premorbid factor.

\section{Clinical course}

The mean \pm standard deviation (SD) onset age of substance use disorders diagnosed according to ICD-9-CM ${ }^{48}$ (24.83 \pm 10.06 years) was earlier than psychiatric illness onset age ( $30.47 \pm 12.10$ years) and the difference between the two age groups was statistically significant (Student's $t$-test, $t=4.6441, d f=128, P<0.001)$. We evidenced that the positive correlation between the onset age of substance use and psychiatric illness was statistically significant (Spearman's rho $=0.4522, P<0.001 ;$ simple linear regression, standard error $[\mathrm{SE}]=0.0862,95 \%$ confidence interval $[\mathrm{CI}]=0.3251-0.6662$, $d f=128, P<0.001)$. As shown in Figure 2, this trend was inverted during the last three decades of life, where psychiatric disease onset preceded substance use.

Table 2 shows the onset age of pathological substance use, diagnosed according to ICD-9-CM. ${ }^{48}$ Onset age was statistically significantly related to the kind of abuse substance ( simple linear regression, $\mathrm{SE}=0.3615,95 \%$ CI $=0.1865-1.6163, d f=137, P<0.05)$. As the survival analysis evidenced, the onset age of psychiatric diseases was conditioned by the kind of abuse substance (logrank test, hazard ratio [HR] $=0.9078, \mathrm{SE}=0.0408,95 \%$ $\mathrm{CI}=0.8313-0.9914, d f=137, P<0.05$ ), whereas the onset age of substance use was related to the time spent in therapeutic communities or psychiatric facilities (log-rank test, $\mathrm{HR}=1.1962, \mathrm{SE}=0.1020,95 \% \mathrm{CI}=1.012-1.4140, d f=119$, $P<0.05)$ and to the follow-up period of psychiatric treatment in the MHS (log-rank test, HR $=1.1399, \mathrm{SE}=0.0304,95 \%$ $\mathrm{CI}=1.0818-1.2011, d f=119, P<0.001)$. 


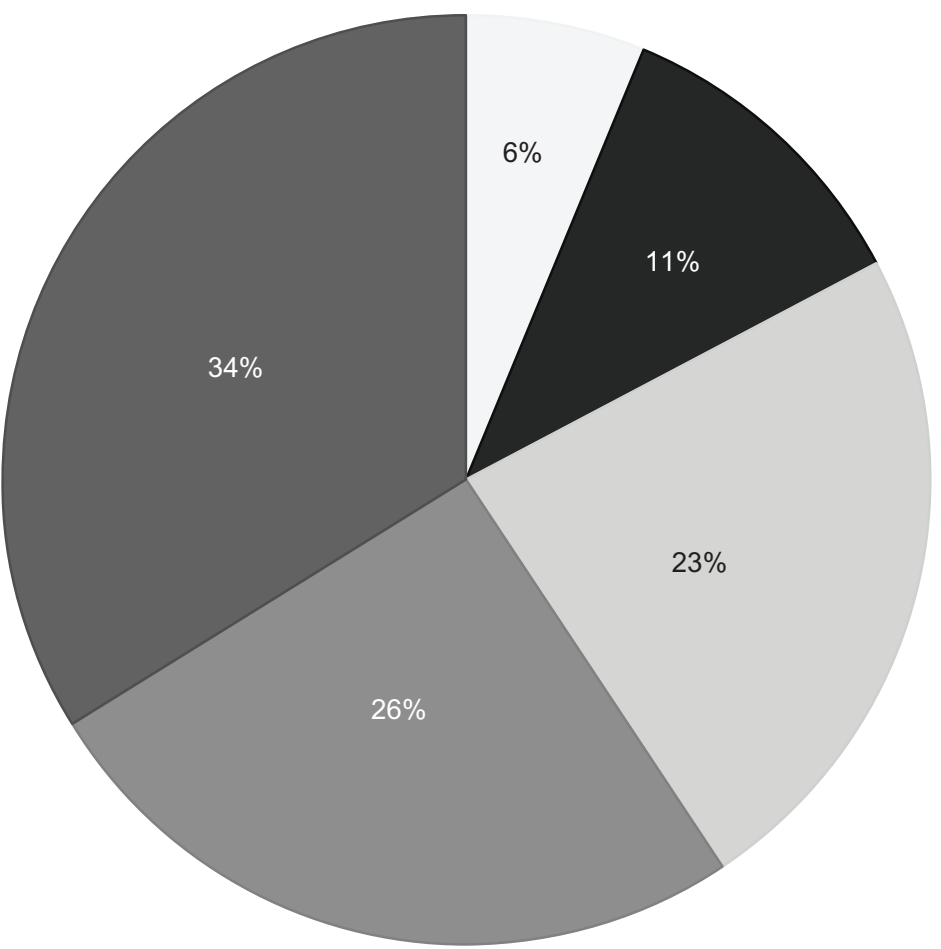

No anamnestic elements observed

Negative events in childhood and/or adolescence

Unknown anamnestic elements
Positive familial history for psychiatric and/or addiction disorders

Positive familial history for psychiatric and/or addiction disorders + negative events in childhood and/or adolescence

Figure I Familial and premorbid history of dual-diagnosis patients.

We did not find any statistically significant difference between substances used at the onset and those used during the study period, although the percentage of patients who used opiates was almost halved during the period of this study (Table 2).

We found that personality disorder was the most frequent diagnosis (38.62\%), followed by bipolar disorder and schizophrenic psychosis, each representing $21.38 \%$ of the

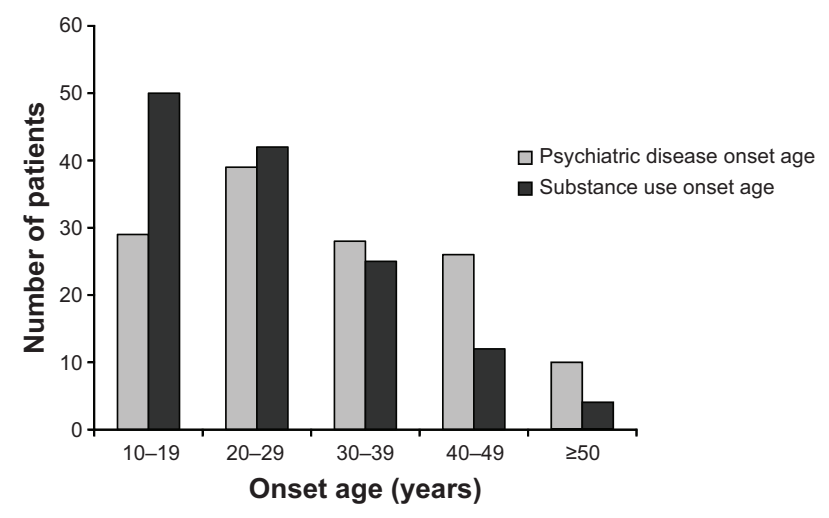

Figure 2 Onset age of psychiatric diseases and substance use. sample (Table 3); psychiatric diagnosis was not statistically significant related to either a specific kind of substance use or a cocktail of substances.

Sex was significantly correlated to psychiatric diagnoses (Pearson $\chi^{2}=13.2134, d f=144, P<0.05$ ): in our sample, schizophrenic psychosis was much more frequent in males (Table 3). Our male patients were more frequently treated with neuroleptic drugs (Pearson $\chi^{2}=17.5814, d f=144$, $P<0.005)$ and more frequently presented familial, health, and social complications (Pearson $\chi^{2}=19.3113, d f=144$, $P<0.005$ ), whereas females more often presented selfthreatening behavior (Table 4).

The follow-up period (Table 5) of SUS treatment was statistically significantly correlated with the onset age of both psychiatric diseases (multiple linear regression, $\mathrm{SE}=0.0648,95 \%$ $\mathrm{CI}=0.0546-0.3113, d f=120, P<0.05)$ and addiction disorder (multiple linear regression, $\mathrm{SE}=0.0719,95 \% \mathrm{CI}=-0.4983$ to $-0.2134, d f=120, P<0.001$ ), whereas the follow-up period of MHS treatment (Table 5) was related only to the onset age of psychiatric diseases (multiple linear regression, $\mathrm{SE}=0.06367$, $95 \% \mathrm{CI}=-0.2937$ to $-0.0416, d f=125, P<0.001)$. 
Table 2 Onset and current substance(s) of abuse and mean age of use onset per substance $(n=\mid 45)$

\begin{tabular}{llll}
\hline Substance of abuse & $\begin{array}{l}\text { Onset substance(s) } \\
\text { of abuse }\end{array}$ & $\begin{array}{l}\text { Current substance(s) } \\
\text { of abuse }\end{array}$ & $\begin{array}{l}\text { Onset age in years per } \\
\text { substance, mean } \pm \text { SD }\end{array}$ \\
\hline Opiates & $22.76 \%$ & $13.10 \%$ & $18.87 \pm 0.93$ \\
Cocaine and amphetamines & $4.14 \%$ & $6.21 \%$ & $23.83 \pm 2.62$ \\
Cannabinoids & $4.14 \%$ & $4.14 \%$ & $16.50 \pm 1.38$ \\
Alcohol & $31.72 \%$ & $33.79 \%$ & $31.41 \pm 1.65$ \\
Cocktail of substances & $37.24 \%$ & $33.79 \%$ & $22.16 \pm 0.99$ \\
$\quad \begin{array}{l}\text { Opiates, 30\% } \\
\text { Cocaine and amphetamines, 30\% }\end{array}$ & & & \\
$\quad \begin{array}{l}\text { Cannabinoids, 19\% } \\
\text { Alcohol, } 11 \%\end{array}$ & & & $24.83 \pm 10.06$ \\
$\quad$ Others, $10 \%$ & & $91.04 \% *$ & \\
Total & $100.00 \%$ & & \\
\hline
\end{tabular}

Notes: $* 8.96 \%$ of our patients were abstinent at the time of last clinical observation.

Abbreviation: SD, standard deviation.

\section{Rehabilitative programs, social support, and professional staffing}

We found a statistically significant correlation between time spent in communities and/or in residential facilities (Table 5) and psychiatric diagnosis (multiple linear regression, $\mathrm{SE}=0.0964,95 \% \mathrm{CI}=0.0607-0.4420 ; d f=144 ; P<0.01)$, in particular for personality disorders (multiple linear regression, $\mathrm{SE}=0.8933 ; 95 \% \mathrm{CI}=-0.1947$ to $-3.3376 ; d f=144$; $P<0.05)$, but not with a specific kind of substance. Most patients $(77 \%)$ were involved in a rehabilitative or social program and $75 \%$ of patients were assisted by one (32\%) or more nurses (43\%) involved in their treatment (Table 5).

\section{Outcome complications}

Only $33 \%$ of patients did not present any complications; the remaining $67 \%$ suffered from many different problems, in similar percentages, as shown in Table 4. As mentioned on page 5, 3rd paragraph, the kinds of problems were different for males and females. The occurrence of complications was statistically significantly related, with a positive

Table 3 Psychiatric diagnosis, sex, and onset age of psychiatric diseases in our sample

\begin{tabular}{|c|c|c|c|c|}
\hline Diagnosis (ICD-9-CM) & $\begin{array}{l}\text { Male, } \\
\mathrm{n}\end{array}$ & $\begin{array}{l}\text { Female, } \\
\text { n }\end{array}$ & Total, n (\%) & $\begin{array}{l}\text { Onset age in } \\
\text { years, mean } \pm \text { SD }\end{array}$ \\
\hline $\begin{array}{l}\text { Organic psychotic conditions } \\
(290.0-294.0)\end{array}$ & 3 & 0 & $3(2 \%)$ & $44.00 \pm 1.00$ \\
\hline $\begin{array}{l}\text { Schizophrenic disorders and } \\
\text { other psychotic disorders } \\
(295.0-295.9 ; 297.0-299.9)\end{array}$ & 27 & 4 & $31(21 \%)$ & $25.97 \pm 1.59$ \\
\hline $\begin{array}{l}\text { Bipolar disorders } \\
(296.0-296.9)\end{array}$ & 16 & 15 & 31 (2I\%) & $36.32 \pm 2.29$ \\
\hline $\begin{array}{l}\text { Neurotic disorders } \\
(300.0-300.9)\end{array}$ & 12 & 6 & $18(12 \%)$ & $35.29 \pm 3.48$ \\
\hline $\begin{array}{l}\text { Personality disorders } \\
(301.0-301.9)\end{array}$ & 32 & 24 & $\begin{array}{l}56(39 \%) \\
34 \text { borderline } \\
8 \text { paranoid } \\
4 \text { histrionic } \\
2 \text { narcissistic } \\
2 \text { dependent } \\
2 \text { avoidant } \\
2 \text { antisocial } \\
2 \text { NS }\end{array}$ & $27.83 \pm 1.58$ \\
\hline Other disorders & 5 & 1 & $6(4 \%)$ & $25.2 \pm 4.96$ \\
\hline Total & 95 & 50 & 145 (100\%) & $30.47 \pm 12.10$ \\
\hline
\end{tabular}

Abbreviations: ICD-9-CM, the International Classification of Diseases, 9th revision, Clinical Modification; n, number; NS, non specified; SD, standard deviation. 
Table 4 Complications and psychopharmacologic therapies in male and female patients

\begin{tabular}{llll}
\hline & Males, $\mathbf{n}$ & Females, $\mathbf{n}$ & Total, $\mathbf{n}(\%)$ \\
\hline Complications & & & $48(33 \%)$ \\
No complications & 32 & 16 & $28(20 \%)$ \\
Familial, employment, legal problems & 21 & 7 & $17(12 \%)$ \\
Health problems & 12 & 5 & $18(12 \%)$ \\
Self-threatening behavior & 4 & 14 & $15(10 \%)$ \\
Social drift & 13 & 2 & $19(13 \%)$ \\
Other problems & 13 & 6 & $145(100 \%)$ \\
Total & 95 & 50 & $13(9 \%)$ \\
Psychopharmacologic therapies & & & $20(14 \%)$ \\
Non pharmacologic therapy & 7 & 6 & $6(4 \%)$ \\
Antipsychotics & 18 & 2 & $4(3 \%)$ \\
Antidepressants & 2 & 4 & $2(1 \%)$ \\
Mood stabilizers & 1 & 3 & $78(54 \%)$ \\
Antipsychotics (long acting) & 2 & 0 & $22(15 \%)$ \\
Antipsychotics and other psychiatric drugs (but not antidepressants) & 55 & 23 & $145(100 \%)$ \\
Antidepressants and other psychiatric drugs (but not antipsychotics) & 10 & 95 \\
Total & 95 & 50 & \\
\hline
\end{tabular}

Abbreviation: $\mathrm{n}$, number.

correlation, both to the number of psychiatric hospitalizations (Spearman's rho $=0.1721, P<0.05$; multiple logistic regression, $\mathrm{OR}=1.7859, \mathrm{SE}=0.5061,95 \% \mathrm{CI}=1.0248-3.1121$, $d f=106, P<0.05)$ and to the number of professionals involved in each patient's treatment (Spearman's rho $=0.2403, P<0.005$; multiple logistic regression, $\mathrm{OR}=4.3604, \mathrm{SE}=2.6403,95 \%$ $\mathrm{CI}=1.3307-14.2872, d f=106, P<0.05)$.

\section{Clinical tests}

The mean \pm SD GCI-S score (4.89 \pm 1.41$)$ was statistically significantly related only to the kind of substance used, in particular alcohol (linear regression, $\mathrm{SE}=0.6270,95 \%$ $\mathrm{CI}=0.0644-2.5490, d f=118, P<0.05)$ and cocktails of different substances (linear regression, $\mathrm{SE}=0.3484,95 \% \mathrm{CI}=0.2116$ 1.5922, $d f=118, P<0.05)$, as described in Table 2 .

Table 5 Hospitalizations, community treatments, pharmacotherapies, rehabilitation, and nursing care in dual-diagnosis patients

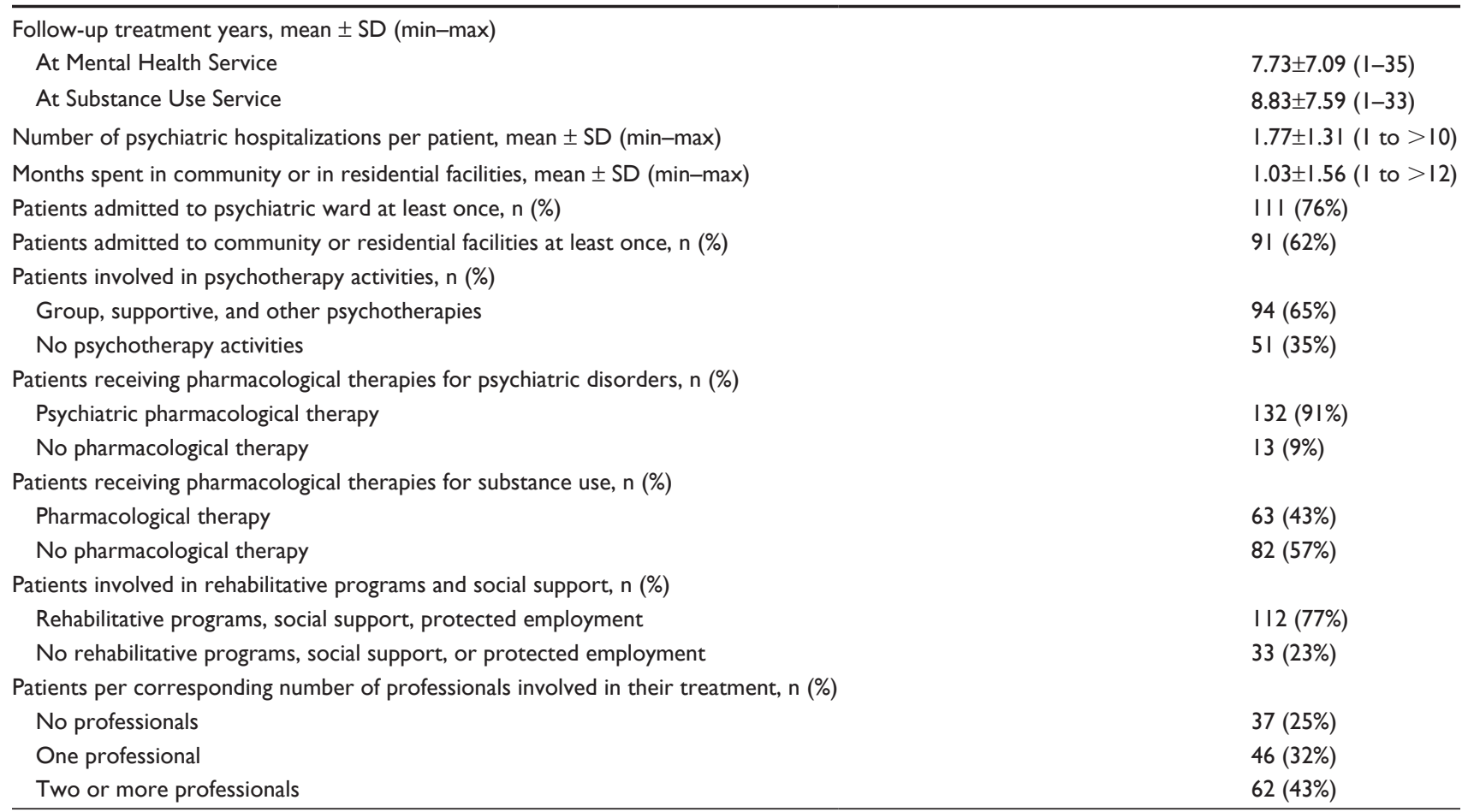

Abbreviations: max, maximum; min, minimum; $n$, number; SD, standard deviation. 
The mean \pm SD GCI-I score (3.51 \pm 1.53$)$ was statistically significantly related only to psychotherapy activities, particularly to group psychotherapy (multiple linear regression, $\mathrm{SE}=0.5759,95 \% \mathrm{CI}=-2.7887$ to $-0.4957, d f=97, P<0.05)$.

The mean \pm SD GAF score obtained during the study period $(56.42 \pm 20.67)$ was statistically significantly different from the mean GAF score at the beginning of psychiatric treatment (44.44 \pm 18.82$)$ (Student's $t$-test, $t=-7.0467$, $d f=251, P<0.001)$ and was statistically significantly related to the number of psychiatric hospitalizations (multiple linear regression, $\mathrm{SE}=1.8065,95 \% \mathrm{CI}=-7.882164$ to -0.6933576 , $d f=97, P<0.05$ ), with a negative correlation (Spearman's rho $=-0.2106, P<0.05)$.

\section{Discussion}

The higher frequency of male patients in our sample corresponds to the sex distribution in the SUS ( $71 \%$ males and $29 \%$ females), but our dual-diagnosis patients were older on average (44 years) than all other patients of the SUS (36 years), suggesting that the occurrence of dual diagnosis needed many years to develop completely.

In accordance with most recent studies, ${ }^{25,52}$ we noticed a high prevalence of psychiatric illness and/or addiction disorders in the family histories of our patients and a much higher occurrence of multiple stressful life events during their childhood and adolescence, which could represent a sort of inherited or acquired vulnerability to the development of both diseases.

Because substance use preceded psychiatric disease in our sample, we could infer that addiction represents the pathological factor that had strongly conditioned mental disease development, but we have to underline, in accordance with the literature, ${ }^{10}$ that a preclinical stage of psychiatric disorders, not recorded in medical charts, could have made people more vulnerable to drug abuse or have induced them to use substances as a sort of self-therapy. Nevertheless, the two disorder onsets were so tightly interconnected as to lead us to hypothesize common risk factors for both diseases. In particular, the kind of substance abuse conditioned the onset age of psychiatric and addiction disorders, as most authors have already evidenced: ${ }^{12,53}$ alcohol abuse began later and was most often related to psychiatric disorder development, whereas cannabis use was closely related to younger age and, probably, to psychosis onset. On the other hand, the chronicity and severity of psychiatric diseases affected addiction development, which could induce a sort of social drift. The patients suffering from Cluster B personality disorders, which was the most frequent psychiatric diagnosis as also reported by other studies, ${ }^{54,55}$ spent a longer time than other patients either in psychiatric communities or residential facilities, probably because of their greater difficulties in social and relational adaptation.

Our sample included "severely ill" patients as attested to by both the high percentage ( $76 \%$, as shown in Table 5) of patients admitted at least once to a psychiatric hospital during the illness course observed and the CGI-S mean score, which was in turn conditioned by the kind of abuse substance, in particular by alcohol. The indicators of our patients' severity were represented by the frequent psychiatric hospitalizations, the presence of several complications, and the high number of professionals involved in the treatment of each patient.

The complications observed were different in males and females: familial, economic, and social maladaptive situation with legal problems were higher in males, whereas females were more vulnerable to self-threatening behaviors and depressive conditions, as the more frequent prescription of antidepressant drugs evidenced. Moreover, males were more frequently treated with antipsychotic drugs, probably due to altered behavior as well as to the higher number of male schizophrenia patients. These observations led us to infer a different evolution of dual diagnosis: an antisocial drift in male patients and a depressive course in female patients.

Outpatient services had to provide long-term supportive therapies, which were conditioned in both services by the onset age of substance use. This data further suggests that dual diagnosis represented a negative prognostic factor because it induced chronicity and reduced the efficacy of therapeutic programs.

We observed that approximately $65 \%$ of patients in our sample were involved in psychotherapy activities, which were related to improvement assessed by the CGI-I scale. In spite of the chronic course of illness and the complications recorded, the final GAF scale scores were statistically significantly higher than the initial ones, suggesting that patients' functioning had improved after long-term treatment.

\section{Conclusion}

The course of dual diagnosis in our sample was chronic, severe, and disabling and required many long-term therapeutic and rehabilitative programs to deal with various disabilities. Health professionals involved in therapy, assistance, and rehabilitation of dual-diagnosis patients should clearly keep in mind the relationship between substance abuse and mental disorder in order to focus on screening tools, damage-reducing interventions, and continuous assistance/support. 


\section{Advantages and limits}

Our study, although limited by its retrospective design, highlighted a sample of patients representative of both Mental Health Service and Substance Use Service populations over a relatively long follow-up period. The sample was selective since it contained only those in treatment and cannot necessarily be generalized to other populations of dual-diagnosis patients. The variables collected were not exhaustive, but sufficiently representative of dual-diagnosis clinical issues.

\section{Implications for future}

Additional studies are necessary to better explore dualdiagnosis topics. In particular, both of the conditions fostering the development of dual diagnosis and its long-term follow-up, differentiated for kind of abuse substance and type of psychiatric disease, should be investigated in larger and more-focused samples in order to identify the patients' vulnerabilities and to improve treatment programs.

\section{Disclosure}

The authors report no conflicts of interest in this work.

\section{References}

1. Brems C, Johnson ME, Wells RS, Burns R, Kletti N. Rates and sequelae of the coexistence of substance use and other psychiatric disorders. Int J Circumpolar Health. 2002;61(3):224-244.

2. Rigliano P. Doppia diagnosi. Tra tossicodipendenza e psicopatologia [Dual diagnosis. Between drug abuse and psychopathology]. Milan, Italy: Cortina Raffaello; 2004. Italian.

3. Regier DA, Farmer ME, Rae DS, et al. Comorbidity of mental disorders with alcohol and other drug abuse. Results from the Epidemiologic Catchment Area (ECA) Study. JAMA. 1990;264(19):2511-2518.

4. Kessler RC, Berglund P, Demler O, Jin R, Merikangas KR, Walters EE. Lifetime prevalence and age-of-onset distributions of DSM-IV disorders in the National Comorbidity Survey Replication. Arch Gen Psychiatry. 2005;62(6):593-602.

5. Kessler RC, Chiu WT, Demler O, Merikangas KR, Walters EE. Prevalence, severity, and comorbidity of 12-month DSM-IV disorders in the National Comorbidity Survey Replication. Arch Gen Psychiatry. 2005; 62(6):617-627.

6. Maremmani I, Zolesi O, Aglietti M, Castrogiovanni P. Disturbi correlati a sostanze [Disorders related to substance]. In: Cassano GB, Pancheri P, Pavan L, et al, editors. Trattato Italiano di Psichiatria. 2nd ed. Milan, Italy: Masson; 1999:1352-1377. Italian.

7. Horsfall J, Cleary M, Hunt GE, Walter G. Psychosocial treatments for people with co-occurring severe mental illnesses and substance use disorders (dual diagnosis): a review of empirical evidence. Harv Rev Psychiatry. 2009; 17(1):24-34.

8. Rush B, Koegl CJ. Prevalence and profile of people with co-occurring mental and substance use disorders within a comprehensive mental health system. Can J Psychiatry. 2008;53(12):810-821.

9. Sterling S, Chi F, Hinman A. Integrating care for people with cooccurring alcohol and other drug, medical, and mental health conditions. Alcohol Res Health. 2011;33(4):338-349.

10. Canaway R, Merkes M. Barriers to comorbidity service delivery: the complexities of dual diagnosis and the need to agree on terminology and conceptual frameworks. Aust Health Rev. 2010;34(3): 262-268.
11. Munro I, Edward KL. Mental illness and substance use: an Australian perspective. Int J Ment Health Nurs. 2008;17(4):255-260.

12. Padwa H, Larkins S, Crevecoeur-Macphail DA, Grella CE. Dual diagnosis capability in mental health and substance use disorder treatment programs. J Dual Diagn. 2013;9(2):179-186.

13. Koob GF. The neurobiology of addiction: a neuroadaptational view relevant for diagnosis. Addiction. 2006;101 Suppl 1:23-30.

14. Wang TY, Lee SY, Chen SL, et al. Association between DRD2, 5-HTTLPR, and ALDH2 genes and specific personality traits in alcoholand opiate-dependent patients. Behav Brain Res. 2013;250:285-292.

15. Gullo MJ, Loxton NJ, Dawe S. Impulsivity: Four ways five factors are not basic to addiction. Addict Behav. Epub 2014 Jan 16.

16. Ellingson JM, Fleming KA, Vergés A, Bartholow BD, Sher KJ. Working memory as a moderator of impulsivity and alcohol involvement: Testing the cognitive-motivational theory of alcohol use with prospective and working memory updating data. Addict Behav. Epub 2014 Jan 23.

17. Sansone RA, Watts DA, Wiederman MW. Borderline personality symptomatology and legal charges related to drugs. Int J Psychiatry Clin Pract. 2014;18(2):150-152.

18. Albein-Urios N, Martinez-Gonzalez JM, Lozano-Rojas O, Verdejo-Garcia A. Executive functions in cocaine-dependent patients with Cluster B and Cluster C personality disorders. Neuropsychology. 2014;28(1):84-90.

19. Conway KP, Compton W, Stinson FS, Grant BF. Lifetime comorbidity of DSM-IV mood and anxiety disorders and specific drug use disorders: results from the National Epidemiologic Survey on Alcohol and Related Conditions. J Clin Psychiatry. 2006;67(2):247-257.

20. Angres D, Bologeorges S, Chou J. A two year longitudinal outcome study of addicted health care professionals: an investigation of the role of personality variables. Subst Abuse. 2013;7:49-60.

21. Krueger RF, Hicks BM, Patrick CJ, Carlson SR, Iacono WG, McGue M. Etiologic connections among substance dependence, antisocial behavior, and personality: modeling the externalizing spectrum. J Abnorm Psychol. 2002;111(3):411-424.

22. Mroziewicz M, Tyndale RF. Pharmacogenetics: a tool for identifying genetic factors in drug dependence and response to treatment. Addict Sci Clin Pract. 2010;5(2):17-29.

23. Wilson CS, Bennett ME, Bellack AS. Impact of family history in persons with dual diagnosis. J Dual Diagn. 2013;9(1):30-38.

24. Maniglio R. The impact of child sexual abuse on health: a systematic review of reviews. Clin Psychol Rev. 2009;29(7):647-657.

25. Wilson DR. Health consequences of childhood sexual abuse. Perspect Psychiatr Care. 2010;46(1):56-64.

26. Schäfer I, Fisher HL. Childhood trauma and psychosis - what is the evidence? Dialogues Clin Neurosci. 2011;13(3):360-365.

27. Sideli L, Mule A, La Barbera D, Murray RM. Do child abuse and maltreatment increase risk of schizophrenia? Psychiatry Investig. 2012;9(2):87-99.

28. Di Lorenzo R, Tomasini E, Ferri P. Psicosi e sostanze: problematiche cliniche e assistenziali in un campione di pazienti ricoverati in un reparto psichiatrico per acuti [Psychosis and substances: problems and clinical care in a sample of patients in a psychiatric department for acute care] Psichiatria and Psicoterapia. 2008;27(1):1-15. Italian.

29. Goerke D, Kumra S. Substance abuse and psychosis. Child Adolesc Psychiatr Clin N Am. 2013;22(4):643-654.

30. Arias F, Szerman N, Vega P, et al. Abuse or dependence on cannabis and other psychiatric disorders. Madrid study on dual pathology prevalence. Actas Esp Psiquiatr. 2013;41(2):122-129.

31. Hambrecht M, Häfner H. Cannabis, vulnerability, and the onset of schizophrenia: an epidemiological perspective. Aust N ZJ Psychiatry. 2000;34(3):468-475.

32. Morgan CJ, Curran HV. Effects of cannabidiol on schizophrenialike symptoms in people who use cannabis. Br J Psychiatry. 2008; 192(4):306-307.

33. Zammit S, Allebeck P, Andreasson S, Lundberg I, Lewis G. Self reported cannabis use as a risk factor for schizophrenia in Swedish conscripts of 1969: historical cohort study. BMJ. 2002;325(7374):1199. 
34. Winklbaur B, Ebner N, Sachs G, Thau K, Fischer G. Substance abuse in patients with schizophrenia. Dialogues Clin Neurosci. 2006; $8(1): 37-43$

35. Suh JJ, Ruffins S, Robins CE, Albanese MJ, Khantzian EJ. Self-medication hypothesis: connecting affective experience and drug choice. Psychoanal Psychol. 2008;25(3):518-532.

36. Li T, Liu X, Zhao J, et al. Allelic association analysis of the dopamine D2, D3, 5-HT2A, and GABA(A)gamma2 receptors and serotonin transporter genes with heroin abuse in Chinese subjects. Am J Med Genet. 2002;114(3):329-335.

37. Pettinati HM, O'Brien CP, Dundon WD. Current status of co-occurring mood and substance use disorders: a new therapeutic target. $\mathrm{Am}$ J Psychiatry. 2013;170(1):23-30.

38. Sánchez-Peña JF, Alvarez-Cotoli P, Rodríguez-Solano JJ. Psychiatric disorders associated with alcoholism: 2 year follow-up of treatment. Actas Esp Psiquiatr. 2012;40(3):129-135.

39. Lucchini A, Bravin S, Cataldini R, et al. Depressione e Dipendenze Patologiche: L'esperienza dei Servizi Territoriali [Depression and Pathological Addictions: The Experience of the Territorial Services]. Milan, Italy: Franco Angeli; 2004. Italian.

40. Maremmani AG, Rovai L, Bacciardi S, et al. The long-term outcomes of heroin dependent-treatment-resistant patients with bipolar 1 comorbidity after admission to enhanced methadone maintenance. $J$ Affect Disord. 2013;151(2):582-589.

41. Sani G, Kotzalidis GD, Vöhringer P, et al. Effectiveness of short-term olanzapine in patients with bipolar I disorder, with or without comorbidity with substance use disorder. J Clin Psychopharmacol. 2013; 33(2):231-235.

42. Heffner JL, Anthenelli RM, Adler CM, Strakowski SM, Beavers J, DelBello MP. Prevalence and correlates of heavy smoking and nicotine dependence in adolescents with bipolar and cannabis use disorders. Psychiatry Res. 2013;210(3):857-862.

43. Gros DF, Milanak ME, Brady KT, Back SE. Frequency and severity of comorbid mood and anxiety disorders in prescription opioid dependence. Am J Addict. 2013;22(3):261-265.

44. Pacek LR, Storr CL, Mojtabai R, et al. Comorbid alcohol dependence and anxiety disorders: a national survey. J Dual Diagn. 2013;9(4).
45. Brady KT, Sinha R. Co-occurring mental and substance use disorders: the neurobiological effects of chronic stress. Am J Psychiatry. 2005; 162(8):1483-1493.

46. Pruessner JC, Champagne F, Meaney MJ, Dagher A. Dopamine release in response to a psychological stress in humans and its relationship to early life maternal care: a positron emission tomography study using [11C]raclopride. J Neurosci. 2004;24(11):2825-2831.

47. Post RM, Kalivas P. Bipolar disorder and substance misuse: pathological and therapeutic implications of their comorbidity and crosssensitisation. Br J Psychiatry. 2013;202(3):172-176.

48. Ministero del Lavoro, della Salute e delle Politiche Sociali. La Classificazione delle Malattie, dei Traumatismi, degli Interventi Chirurgici e delle Procedure Diagnostiche e Terapeutiche: Versione Italiana della ICD-9-CM [International Classification of Diseases, 9th revision, Clinical Modification, 2007]. Rome, Italy: Istituto Poligrafico e Zecca dello Stato, Libreria dello Stato; 2008. Italian.

49. Rush AJ Jr, First MB, Blacker D. Handbook of Psychiatric Measures. 2nd ed. Washington, DC: American Psychiatric Publishing; 2007.

50. Luborsky L. Clinicians' judgments of mental health: a proposed scale. Arch Gen Psychiatry. 1962;7(6):407-417.

51. Stata Corp LP. Stata Statistical Software: Release 12. College Station, TX: Stata Corp LP, 2011.

52. Arcos-Burgos M, Vélez JI, Solomon BD, Muenke M. A common genetic network underlies substance use disorders and disruptive or externalizing disorders. Hum Genet. 2012;131(6):917-929.

53. Connor JP, Gullo MJ, Chan G, Young RM, Hall WD, Feeney GF. Polysubstance use in cannabis users referred for treatment: drug use profiles, psychiatric comorbidity and cannabis-related beliefs. Front Psychiatry. 2013;4:79.

54. Sher KJ, Trull TJ. Substance use disorder and personality disorder. Curr Psychiatry Rep. 2002;4(1):25-29.

55. Sansone RA, Sansone LA. Substance use disorders and borderline personality: common bedfellows. Innov Clin Neurosci. 2011; 8(9):10-13.
Neuropsychiatric Disease and Treatment

\section{Publish your work in this journal}

Neuropsychiatric Disease and Treatment is an international, peerreviewed journal of clinical therapeutics and pharmacology focusing on concise rapid reporting of clinical or pre-clinical studies on a range of neuropsychiatric and neurological disorders. This journal is indexed on PubMed Central, the 'PsycINFO' database and CAS,

\section{Dovepress}

and is the official journal of The International Neuropsychiatric Association (INA). The manuscript management system is completely online and includes a very quick and fair peer-review system, which is all easy to use. Visit http://www.dovepress.com/testimonials.php to read real quotes from published authors. 